\title{
Adsorption and intercalation of anionic surfactants onto layered double hydroxides-XRD study
}

\author{
R ANBARASAN*, W D LEE $^{\dagger}$ and S S IM \\ Department of Polymer Technology, Kamaraj College of Engineering and Technology, Virudhunagar 626 001, India \\ 'Department of Fibre and Polymer Engineering, Hanyang University, Seoul, South Korea
}

MS received 12 October 2004; revised 10 January 2005

\begin{abstract}
Layered double hydroxides (LDH) with brucite like structure was modified with various anionic surfactants containing sulfonate, carboxyl, phosphonate and sulfate end group through ion-exchange method. XRD reports indicated that the sulfonate group containing surfactants led to an adsorption process whereas the sulfate, carboxyl and phosphonate group containing surfactant led to an intercalation process. This can be evidenced from the change in basal spacing of LDH. The presence of anionic surfactants in the LDH was supported by FTIR spectroscopy. The FTIR spectrum indicated that complete removal of carbonate anion from the inter layer space of LDH is very difficult. The phosphonate intercalated HT showed less thermal stability than pristine LDH.
\end{abstract}

Keywords. LDH; ion-exchange; anionic surfactants; XRD; FTIR spectroscopy; TGA.

\section{Introduction}

Recently the application of layered double hydroxides (LDH) has been increased abnormally due to excellent catalytic activity. For example, in the hydroxylation of alkenes (Friedrich et al 2003), oxidation of alcohols to aldehydes and ketones (Matsushita et al 1999; Friedrich et al 2001; Kakiuchi et al 2001). Nowadays its application has been extended to prepare polymer-nanocomposites with improved mechanical properties. However, there exists incompatibility between the inorganic nature of LDH and organic nature of polymer. This problem can be sorted out by modification of LDH (i.e.) the hydrophobicity of LDH can be increased by the introduction of an organic surfactant into LDH structure. This is possible in $\mathrm{LDH}$ due to its excellent anionic exchange property. Stereoselective intercalation of hexose into LDH was successfully reported by Aisawa et al (2004). The literature survey inferred that the LDH was modified with aspartic acid (Yuan et al 2004), EDTA (Lukashin et al 2003), 4hydroxy-3-methoxy cinnamic acid (He et al 2003), glutaric acid (Lee et al 2003) and cinnamate anion (Greenwell et al 2003). Recently Choy et al (2004) reported the folic acid intercalated LDH and thus modified LDH was used as an drug reservoir. Arco and co-workers (2004) modified the LDH with adipate anion and the resultant hybrids were characterized by XRD, TGA, FTIR, SEM, EDX, elemental analysis and nitrogen adsorption method. Adsorption of DBSA onto LDH was reported by You et al

*Author for correspondence (anbu_may3@yahoo.co.in)
(2002). Sulfanato salen manganese complex intercalated $\mathrm{Zn} / \mathrm{Al} \mathrm{LDH}$ report is available (Battacharjee and Anderson 2004). Bifunctional short chain anionic surfactant such as tartrate and succinate intercalated $\mathrm{Zn} / \mathrm{Cr} \mathrm{LDH}$ was prepared by Prevot and co-workers (1998). Terephthalate and benzoate modified $\mathrm{Mg} / \mathrm{Al} \mathrm{LDH}$ was reported by Kooli et al (1996). Xu and Braterman (2003) reported the morphological changes of DBSA modified LDH. In the present communication we report here about the modification of $\mathrm{LDH}(\mathrm{Mg} / \mathrm{Al}=2 \cdot 1)$ with various functionalized anionic surfactants and the final hybrids are characterized by XRD, FTIR spectroscopy and TGA methods.

\section{Experimental}

Hydrotalcite (HT), a LDH with carbonate anion as an inter layer anion $(\mathrm{Mg} / \mathrm{Al}=2 \cdot 1$ and having a layer thickness, $0.48 \mathrm{~nm}$ ) is a gift sample from KICET (Korea) and used as such. Sodium salts of dodecyl benzenesulfonic acid (DBSA), dodecyl sulfate (DDS) and sulfonated isophthalic acid (SIPA) were purchased from Aldrich chemicals, Korea and used as received. Dodecyl phosphonic acid (mono ester) (DDP) (Lancaster, Korea), aleuritic acid (AA) (Lancaster, Korea) and sebacic acid (SA) (Aldrich Chemicals, Korea) and other chemicals were purchased and used without further purification. The chain length of the long chain organic aliphatic surfactants was calculated based on Isupov's (Isupov and Chupakhina 2001) semiempirical formula.

$5 \mathrm{~g}$ of HT was placed in a $500 \mathrm{ml}$ three-necked round bottom flask (RBF) filled with $250 \mathrm{ml}$ de-ionized water. The middle neck was used to attach the stirrer and the 
remaining two used as nitrogen inlet and outlet. $10 \mathrm{~g}$ of surfactant was added to the content of RBF with vigorous stirring under inert atmosphere at $70^{\circ} \mathrm{C}$ for $48 \mathrm{~h}$ in an alkaline medium. The ratio of carbonate to surfactant was $1: 2$ because the divalent carbonate anion was ionexchanged by the mono valent surfactant. After $48 \mathrm{~h}$ of ion-exchange process, the precipitates were filtered and washed by de-ionized water to remove sodium carbonate formed during the ion-exchange reaction and the precipitate was dried at room temperature for $48 \mathrm{~h}$. The white solid thus obtained was grounded and stored in a vial bottle. HT before and after ion-exchange process was characterized by XRD (powder sample, Rigaku Rint 2000 (Japan) diffractometer at room temperature with $\mathrm{CuK} \alpha 1$ radiation, the angle $2 \theta$ was scanned from 2 to $70^{\circ}$ ) and FTIR spectroscopy ( $\mathrm{KBr}$ pelletization, Nicolet 760 magna IR spectrometer). Thermal stability of HT before and after modification was checked by using the TGA analysis performed under air purge at the heating rate of $10^{\circ} \mathrm{C} / \mathrm{min}$ by using the SDT 2960 TGA instrument.

The basal spacing (from Bragg's equation) $(d)$, inclined angle $(\phi)$ and gallery height $(L)$ can be calculated from (1), (2) and (3), respectively.

$$
\begin{aligned}
& d=\frac{\lambda}{2 \sin \theta}, \\
& \operatorname{Sin} \theta=\frac{\text { Basal spacing of } d_{003} \text { plane }- \text { thickness of layer }}{\text { Length of the organic anionic surfactant }}
\end{aligned}
$$

Gallery height, $L=$ Basal spacing $(d)$ - thickness of layer,

where, $d$ is the basal spacing, $\theta$, the diffraction angle, $\lambda$, the wave length, $\phi$, the contact angle and $L$ is gallery height in $\mathrm{nm}$.

\section{Results and discussion}

XRD of pure HT (figure 1a) showed $d_{003}\left(11.47^{\circ}\right), d_{006}$ $\left(23 \cdot 02^{\circ}\right), d_{012}\left(34 \cdot 59^{\circ}\right), d_{015}\left(39 \cdot 27^{\circ}\right), d_{018}\left(46 \cdot 17^{\circ}\right), d_{110}\left(60 \cdot 64^{\circ}\right)$ and $d_{113}\left(61.94^{\circ}\right)$ crystal planes with the basal spacing of $0.769 \mathrm{~nm}$. Among those, $d_{003}$ plane peak is responsible for the increase of interlayer spacing. After modification with anionic surfactants, the $d_{003}$ plane peak was shifted towards lower $2 \theta$ value (due to increase of basal spacing) and the increase of inter layer space depended on the intercalation nature of functional group, size of surfactants and alkyl chain length of anionic surfactants. In the case of SA modified HT (HT-SA) (figure 1b), a new peak appeared at the $2 \theta$ value of $6.92^{\circ}$ with the basal spacing and orientation angle value of $1.27 \mathrm{~nm}$ and $26.7^{\circ}$, respectively. And some other new peaks also appeared due to the intercalated SA. Yuan et al (2004) explained the Laspartic acid intercalated LDH by co-precipitation method with different basal spacings. Presence of a peak at $11.47^{\circ}$ even after modification infers that part of the HT is in unmodified form due to high charge density of HT. This high charge density of HT can be explained on the basis of intra-molecular substitution of $\mathrm{Al}^{3+}$ by $\mathrm{Mg}^{2+}$ ions. During the ion-exchange process, the SA approached the hydroxyl layer of $\mathrm{LDH}$ in the parallel direction $\left(26.7^{\circ}\right)$ with mono layer structure formation. The increase in basal spacing without layer degradation confirms the intercalation of SA into HT structure and parallel alignment in the inter layer space of HT. In the case of AA modified (HT-AA) (figure 1c) system we could not see any crystalline peaks due to the degradation of layer structure by the high acidity nature of AA. Layer degradation led to the formation of amorphous products such as $\mathrm{Al}(\mathrm{OH})_{3}, \mathrm{Mg}(\mathrm{OH})_{2}$ etc. That we were unable to calculate the increase in basal spacing, orientation angle and nature of layer structure formation.

The DDP intercalated HT (HT-DDP) (figure 1d) showed the $2 \theta$ value of $2.89^{\circ}$ corresponding to the basal spacing of $3.05 \mathrm{~nm}$ with bi-layer structure formation. The orientation angle was calculated to be $90^{\circ}$ i.e. by perpendicular approach (table 1). The high basal spacing value of HTDDP system confirms the strong intercalating capacity of mono phosphonate functional DDP. Here also we observed two more new peaks $\left(5.67^{\circ}\right.$ and $\left.8.53^{\circ}\right)$ due to exfoliation of HT.

In the case of DBSA modified (HT-DBSA) system, the basal spacing was found to slightly decrease $(0.751 \mathrm{~nm})$ (table 1). The decrease in basal spacing (figure 1b) after modification may be associated with the removal of inter layer water molecules or rearrangement of octahedral to tetrahedral geometry of Al ion. Pavan et al (2000) explained the sorption of various sulfonates and sulfates intercalated LDH. The present system showed the increased peak intensities of $d_{003}$ and $d_{006}$ crystalline peaks.

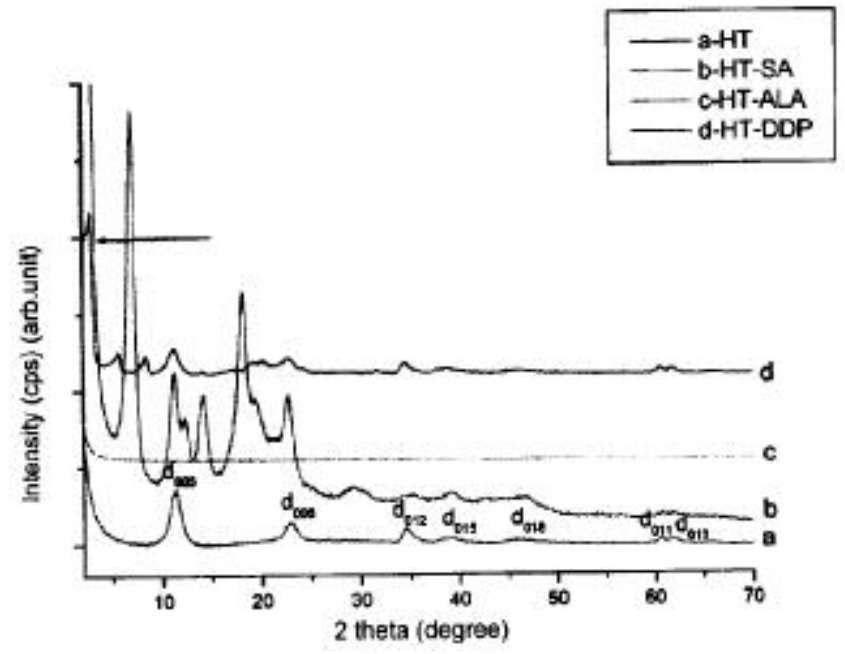

Figure 1. XRD of a. HT, b. HT-SA, c. HT-AA and d. HTDDP. 
Table 1. XRD reports of HT before and after modification with various surfactants.

\begin{tabular}{lrcccc}
\hline System & $2 \theta\left(^{\circ}\right)$ & $\begin{array}{c}\text { Basal spacing, } \\
d(\mathrm{~nm})\end{array}$ & $\begin{array}{c}\text { Orientation angle, } \\
\theta\left({ }^{\circ}\right)\end{array}$ & $\begin{array}{c}\text { Lallery height } \\
(\mathrm{nm})\end{array}$ \\
\hline HT & 11.42 & 0.769 & - & - & 0.289 \\
HT-DBSA & 11.77 & 0.751 & - & - & 0.271 \\
HT-DDS & 4.22 & 2.091 & 38.9 & Monolayer & 1.611 \\
HT-SIPA & 11.24 & 0.786 & - & - & 0.306 \\
HT-SA & 6.99 & 1.263 & $26 \cdot 7$ & Monolayer & 0.783 \\
HT-DDP & 2.89 & 2.879 & 90 & Bilayer & $2 \cdot 879$ \\
HT-AA & - & - & - & - & - \\
\hline
\end{tabular}

The decrease in basal spacing and increase in peak intensity stressed that the anionic surfactant, DBSA, is physically adsorbed on the surface of HT through hydrogen bonding in an well ordered manner without layer degradation of LDH. Two new peaks appeared at $53 \cdot 2^{\circ}$ and $56.4^{\circ}$ due to the adsorbed DBSA molecules.

HT-DDS hybrid (figure 2c) showed two new peaks at lower $2 \theta$ value (due to $d_{001}$ and $d_{002}$ planes) and confirmed the intercalation of DDS molecules into LDH. The intercalation of DDS into LDH was further evidenced by the calculation of basal spacing $(2.091 \mathrm{~nm})$ and gallery height $(1.611 \mathrm{~nm})($ table 1$)$. The orientation angle (OA) was calculated to be $38.9^{\circ}$ with mono layer structure. The $\mathrm{OA}$ itself explains the approach of anionic surfactant to the hydroxide layer of LDH. The OA is in midway between the parallel and perpendicular approach. And hence confirms the absence of pillar like structural arrangement of surfactant in the inter layer space of LDH. New peaks around the $2 \theta$ value of $20^{\circ}$ is due to the crystalline peaks of DDS molecules. The XRD results of HT-DDS indicated that the intercalation of DDS into LDH took place without layer degradation. In the case of HT-SIPA (figure 2d) system, the basal spacing $(0.786 \mathrm{~nm})$ did not increase greatly. This slight increase in basal spacing means the adsorption of SIPA on the surface of HT through hydrogen bonding (hydrogen bonding between $\mathrm{SO}_{3}$ group of SIPA and $\mathrm{OH}$ group of $\mathrm{LDH}$ ) without layer degradation. The adsorption of SIPA on the surface of LDH was further evidenced by the calculation of gallery height $(0.306 \mathrm{~nm})$. The gallery height is smaller than that of the length of SIPA (table 1). The intensity of the crystalline peaks of HT-SIPA is higher and sharper than the pristine LDH.

The presence of anionic surfactants in the HT structure can be further supported by FTIR spectroscopy (figure 3). The pure HT (figure 3a) showed a broad peak at $3473 \mathrm{~cm}^{-1}$ due to $\mathrm{OH}$ stretching. Carbonate and metal hydroxide stretching appeared at 1390 and $664 \mathrm{~cm}^{-1}$, respectively. Another small peak that appeared at $1644 \mathrm{~cm}^{-1}$ is due to the bending vibration of water. In the case of modified HT (MHT) also we can observe all the above mentioned peaks, particularly, carbonate peak. This indicates that complete removal of carbonate from HT is very difficult. Moreover, $\mathrm{CO}_{2}$ can be easily adsorbed from the

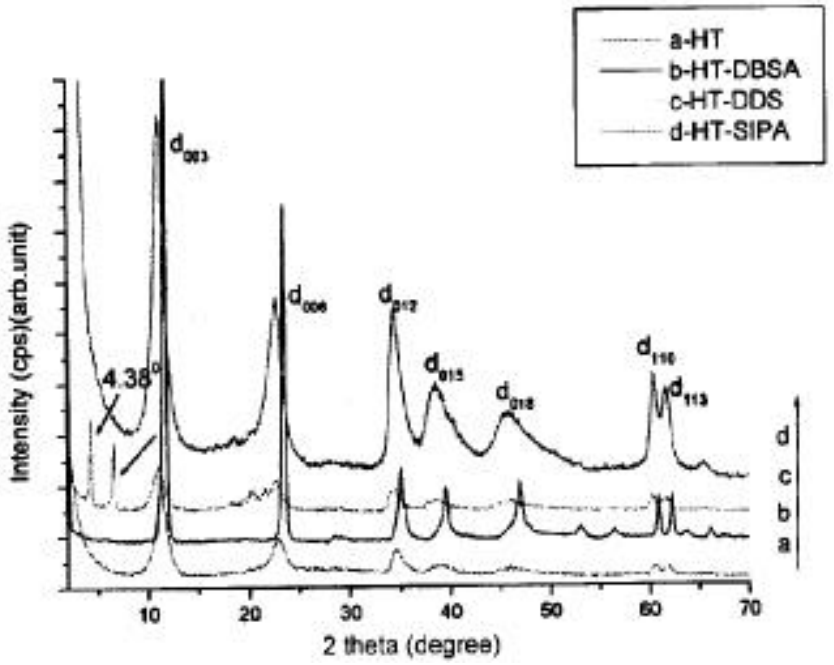

Figure 2. XRD of a. HT, b. HT-DBSA, c. HT-DDS and d. HT-SIPA.

atmosphere during the filtration process and hence reconstitution of $\mathrm{CO}_{3}-\mathrm{HT}$.

In the case of SA modified HT (figure 3b) system the important peaks are characterized here: a peak appearing at $3696 \mathrm{~cm}^{-1}$ inferred the presence of free $\mathrm{OH}$ group. $3463 \mathrm{~cm}^{-1}$ - inter molecular hydrogen bonded $\mathrm{OH}$ stretching, anti-symmetric and symmetric stretching of $\mathrm{C}-\mathrm{H}$ can be visualized from 2928 and $2859 \mathrm{~cm}^{-1}$ peaks, respectively. $\mathrm{C}-\mathrm{H}$ asymmetric deformation vibration appeared at $1461 \mathrm{~cm}^{-1}$. Normally for long chain aliphatic carboxylic acids the carbonyl stretching will not appear. But in the present system it showed one small shoulder at $1718 \mathrm{~cm}^{-1}$ and confirmed the presence of carbonyl group.

From the case of AA modified HT (figure 3b) system we observed the same $\mathrm{C}-\mathrm{H}$ symmetric and anti-symmetric stretching vibrations with some new peaks, even then the LDH structure is degraded. Peak at $1358 \mathrm{~cm}^{-1}$ is plane deformation vibration of primary and secondary alcohols and $1064 \mathrm{~cm}^{-1}$ peak is due to saturated primary alcohol. These peaks indicated that the anionic surfactant, AA, was physically adsorbed onto the degraded LDH structure. In the case of DDP modified HT (figure 3c) system the peaks due to phosphonic acid appeared between 1126 and $1032 \mathrm{~cm}^{-1}$. The $\mathrm{OH}$ deformation vibration 
can be seen at $1364 \mathrm{~cm}^{-1}$. The remaining peaks are attributed to the $\mathrm{C}-\mathrm{H}$ and $\mathrm{OH}$ vibrations.

DBSA modified HT system (figure $4 \mathrm{~b}$ ) showed some new shoulders other than LDH peaks around 941$1200 \mathrm{~cm}^{-1}$ due to $\mathrm{SO}_{3}$ stretching vibrations. Here also we can observe a peak due to carbonate stretching and confirm the presence of carbonate ion in the DBSA modified LDH. The FTIR spectrum of HT-DDS is shown in figure 4c. The new peaks are characterized below: $2919 \mathrm{~cm}^{-1}-\mathrm{C}-\mathrm{H}$ anti-symmetric stretching, 2848-C-H symmetric stretching, $984-1200 \mathrm{~cm}^{-1}-\mathrm{SO}_{4}$ stretching. Figure $4 \mathrm{~d}$ exhibits the FTIR spectrum of HT-SIPA. Peaks between 1000 and $1200 \mathrm{~cm}^{-1}$ are due to $-\mathrm{SO}_{3}$ stretching and the ring deformation vibration is observed at $1538 \mathrm{~cm}^{-1}$.

The LDH was modified with various sulfonate, phosphonate, carboxyl and sulfate containing anionic surfac-

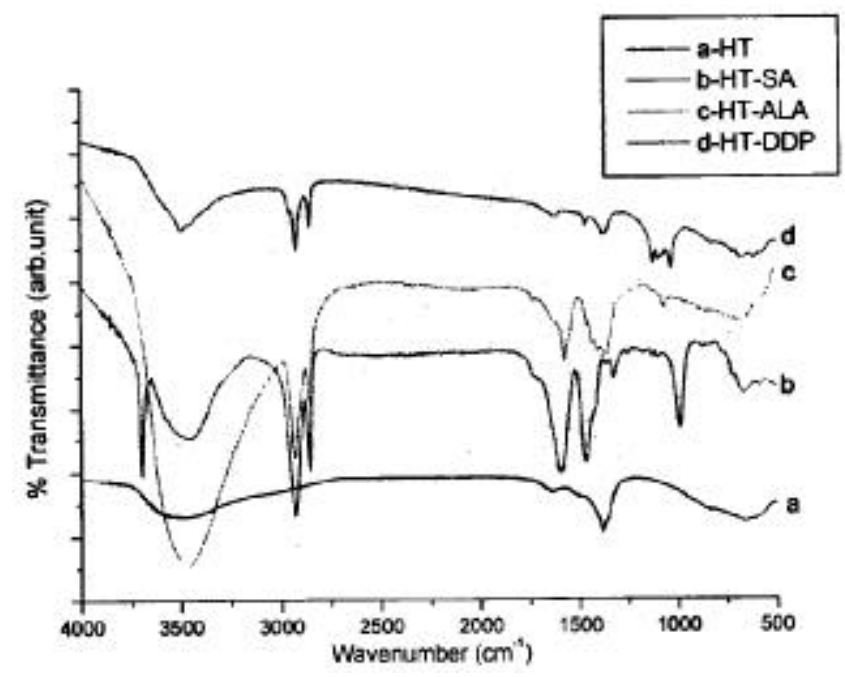

Figure 3. FTIR spectra of a. HT, b. HT-SA, c. HT-AA and d. HT-DDP.

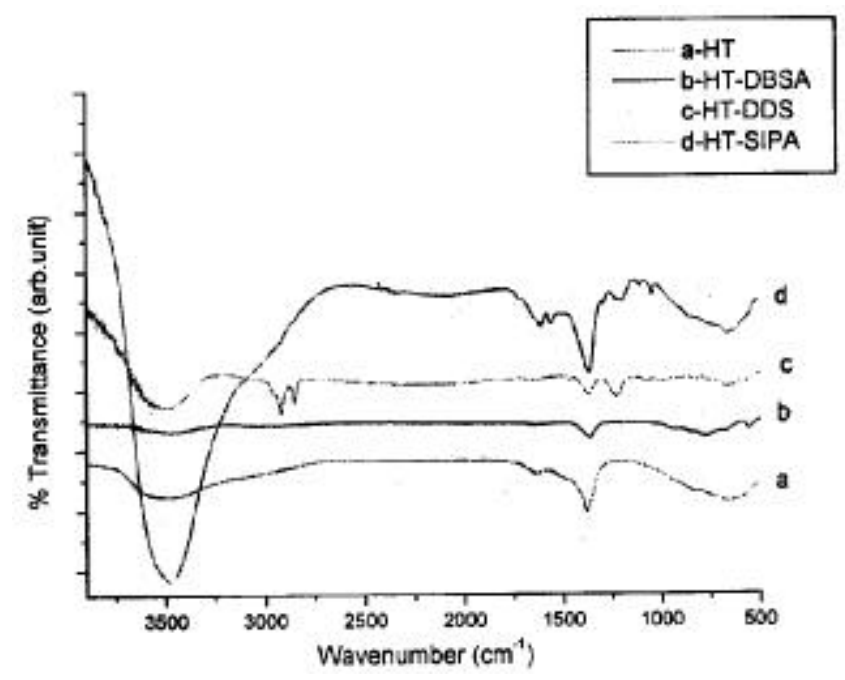

Figure 4. FTIR spectra of a. HT, b. HT-DBSA, c. HT-DDS and d. HT-SIPA. tants through ion-exchange method and led to different reaction mechanisms. XRD reports indicated that the sulfonated surfactants (DBSA) led to adsorption (due to hydrogen bonding) onto LDH structure with increased intensity of crystalline peaks (by well ordered arrangement of surfactant on the surface of LDH). The sulfate, phosphonate and carboxyl functionalized surfactants led to real intercalation process without pillar like structure formation. SIPA has both carboxyl and sulfonate functionalities but due to bulky nature of phenyl ring it could not lead to an intercalation process. In the case of AA (containing both hydroxyl and carboxyl functionalities) due to high acidic nature, it leads to the degradation of layer structure. The FTIR spectrum supports the presence of anionic surfactants in the $\mathrm{LDH}$ structure. It also reveals that complete removal of $\mathrm{CO}_{3}$ anion by the anionic surfactants from the inter layer space of LDH is not possible. This is because of small size of $\mathrm{CO}_{3}$ anion and ready uptake of $\mathrm{CO}_{2}$ from the atmosphere.

The TGA of HT (figure 5a) and HT-DDP (figure 5b) showed three-step degradation mechanism. In HT (figure 5a) the first weight loss step up to $200^{\circ} \mathrm{C}$ is due to the removal of physisorbed and interlayer water molecules. The major second weight loss step is due to the removal of water molecules by de-hydroxylation process $\left(345^{\circ} \mathrm{C}\right)$. The third minor weight loss step is due to the decomposition of inter layer carbonate anion. In the case of DDP modified HT (figure 5b) system also the TGA showed three-step degradation process. Before $200^{\circ} \mathrm{C}$, the water molecules and the DDP anions were removed from the HT. Now the HT structure becomes distorted and major de-hydroxylation occurred at somewhat lower temperature $\left(325^{\circ} \mathrm{C}\right)$. On critical analysis the TGA inferred that degradation of interlayer anion took place before de-hydroxylation process in the case of HT-DDP and hence showed less thermal stability than the original HT.

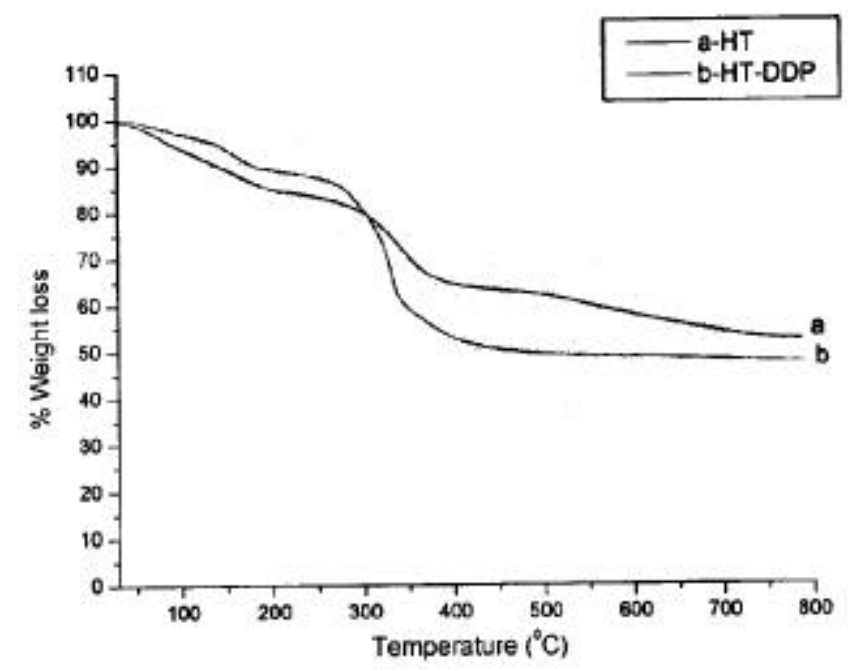

Figure 5. TGA of a. HT and b. HT-DDP. 
Table 2. TGA reports of HT before and after modification with DDP.

\begin{tabular}{lccccc}
\hline System & $\begin{array}{c}\text { \% wt. loss at } \\
200^{\circ} \mathrm{C}\end{array}$ & $\begin{array}{c}\% \text { wt. loss at } \\
400^{\circ} \mathrm{C}\end{array}$ & $\begin{array}{c}\% \text { wt. loss at } \\
500^{\circ} \mathrm{C}\end{array}$ & $\begin{array}{c}\% \text { wt. loss at } \\
600{ }^{\circ} \mathrm{C}\end{array}$ & $\begin{array}{c}\% \text { wt. residue } \\
\text { remains }\end{array}$ \\
\hline HT & 93.01 & 70.37 & 66.80 & 61.97 & 56.95 \\
HT-DDP & 89.50 & 52.98 & 49.50 & 48.89 & 48.42 \\
\hline
\end{tabular}

Table 2 explains the thermal stability of HT before and after modification with DDP.

\section{Conclusions}

XRD results inferred that the sulfonate containing anionic surfactants led to adsorption process and this process is independent of alkyl chain length and size. The high acidity nature of AA degraded the LDH structure. FTIR spectra confirmed the possible interaction between $\mathrm{LDH}$ and anionic surfactants. TGA declared the lower thermal stability of DDP modified HT.

\section{References}

Aisawa S, Hirahara H and Narita E 2004 Chem. Lett. 33306 Arco M, Carriazo D, Martin C and Rives V 2004 Inorg. Chem. 43375

Battacharjee S and Anderson J A 2004 Chem. Commun. 554

Choy J H, Jung J S, Oh J M and Han O J 2004 Biomaterials 25 3059
Friedrich H B, Khan F, Singh N and Staden M 2001 Synlett. 6 869

Friedrich H B, Govender M and Onani M O 2003 Chem. Commun. 2922

Greenwell C, Jones W and Coveney P V 2003 J. Mol. Struct. 64775

He L, Yin S and Sato T 2003 Solid State Chem. 7751

Isupov V P and Chupakhina L E 2001 Solid State Ionics 141231

Kakiuchi N, Nishimura T and Uemura S 2001 Bull. Chem. Soc. Jpn 74165

Kooli F, Cjisem C, Vucelic M and Jones W 1996 Chem. Mater. 81969

Lee J H, Ree S W and Jung D Y 2003 Chem. Commun. 2740

Lukashin V, Vertegel A and Tretyakov D 2003 J. Nanopart. Res. 5455

Matsushita T, Ebitani K and Kaneda K 1999 Chem. Commun. 265

Pavan P C, Crepaldi E L and Valim J B 2000 J. Colloid Inter. Sci. 229346

Prevot V, Forano C and Besse P 1998 Inorg. Chem. 374293

Xu Z P and Braterman P S 2003 J. Mater. Chem. 13268

Yuan Q, Wei M, Wang Z and Duan X 2004 Clays Clay Miner. 5240

You Y, Zhao H and Vance G F 2002 J. Mater. Chem. 12907 